\title{
IBU RUMAH TANGGA DALAM MENUMBUHKEMBANGKAN EKONOMI KELUARGA DI TINJAU DARI HUKUM ISLAM
}

\author{
Mutmainna \\ Mahasiswa Prodi Hukum Ekonomi Syariah FAl Unismuh Makassar \\ Abstrak
}

Jenis penelitian ini merupakan penelitian kuantitatif yang dilakukan di Desa Buttu Batu Kecamatan Enrekang Kabupaten Enrekang. Penelitian ini termasuk penelitian kuantitatif yang bertujuan untuk mengetahui :Pengaruh Terapan Peran Ibu Rumah Tangga Dalam Menumbuhkembangkan Ekonomi Keluarga Di Tinjau Dari Hukum Islam Studi Kasus Perempuan Pelaku Kegiatan Usaha Rumahan. Dalam penelitian ini terdiri dari tiga variable yaitu, $\varepsilon$ Peran lbu, $£$ Hukum Islam, $\beta$ Ekonomi Keluarga.

Total sampling dalam penelitian ini berjumlah 62 orang. Pengumpulan data dilakukan dengan cara penyebaran kuesioner atau angket. Adapun yang menjadi populasi dalam penelitian ini adalah jumlah para pekerja rumahan di Desa Buttu Batu Kecamatan Enrekang Kabupaten Enrekang sebanyak 200 orang, dengan menggunakan rumus Sloving maka menghasilkan sampel sebanyak 62 sampel. Selanjutnya, data yang diperoleh melalui instrument tersebut kemudian diolah melalui analisis regresi linear berganda dengan bantuan aplikasi Partial Least Square (PLS).

Hasil penelitian menunjukkan bahwa margin peran ibu rumah tangga dalam mendorong kesejahteraan keluarga, berpengaruh positif dan signifikan dari hasil analisis inferensial yang menggunakan uji $t$ dengan rumus regresi linear berganda menunjukkan bahwa nilai $\boldsymbol{t}_{\text {hitung }}$ lebih besar dari pada nilai $\mathbf{t}_{\text {tabel. }}$.

Kata Kunci : Peran ibu rumah tangga dalam mendorong ekonomi keluarga

\begin{abstract}
This research type is quantitative research conducted in Buttu Batu Village Enrekang Sub-District Enrekang Regency. This research includes quantitative research which aims to know: Applied Influence Role of Housewives in Growing Family Economics in Review of Islamic Law Case Study of Women Business Activity Actors. In this study consists of three variables namely, Role of Mother, Islamic Law, and Family Economy.
\end{abstract}

Total sampling in this study amounted to 62 people. Data collection is done by distributing questionnaires or questionnaires. As for the population in this study is the number of home workers in the Village Buttu Batu Enrekang District Enrekang District as many as 200 people, using the formula of Solving then produce a sample of 62 samples. Furthermore, the data obtained through the instrument is then processed through multiple linear regression analysis with the help of Partial Least Square (PLS) application.

The results showed that the margin of role of housewife in encouraging family welfare, have positive and significant effect from result of inferential analysis using $t$ test with multiple linear regression formula show that count is bigger than table value.

Keywords: The role of housewives in encouraging the family economy 


\section{A. PENDAhUlUaN}

Kehidupan modern kaum perempuan dapat bekerja dan berkarier di mana saja selagi ada kesempatan. Pada tempo dulu, ruang lingkup dan peran perempuan hanya terbatas pada sektor rumah tangga saja. Fungsi perempuan secara umum adalah mengurus rumah tangga, membesarkan anak-anak, serta mengurus kepentingan suami dan urusan-urusan lain yang berkenaan dengan kehidupan di dalam rumah tangga. Perempuan yang dibebani masalah-masalah ekonomi sangat sedikit dibandingkan perempuan sekarang. Sekarang ini perempuan diperbolehkan bekerja di luar rumah untuk membantu masalah ekonomi dalam keluarga atau karena masyarakat membutuhkan keahlian mereka.

Tingkat pendidikan para wanita sekarang sudah sama sejajarnya dengan pria. Tidak ada lagi hambatan yang menghalangi wanita untuk sekolah setinggi-tingginya sehingga keputusan bekerja adalah sebuah cara untuk mengaktualisasikan diri.

Bekerja untuk mencari nafkah bagi seorang muslim adalah suatu kewajiban serta upaya yang sungguhsungguh dengan mengerahkan seluruh aset, pikiran, dan zikirnya. Pekerjaan dapat mengaktualisasikan atau menampakkan arti dirinya sebagai hamba Allah yang harus menundukkan dunia dan menempatkan dirinya sebagai bagian dari masyarakat yang terbaik atau dengan kata lain bahwasanya hanya dengan bekerja untuk mencari nafkah manusia itu bisa memanusiakan dirinya.

Sebuah rumah tangga dalam keluarga, terkadang semua kebutuhan hidup sehari-harinya didominasi oleh pihak istri, bukan hanya dari segi pemeliharaan dan pengasuhan anak tetapi juga dalam hal nafkahpun istrilah yang memegang kendalinya. Istri bekerja untuk menafkahi keluarga akan menimbulkan beberapa konsekuensi. Misal, harus meninggalkan anak-anak di rumah. Istri juga tidak lagi mempunyai waktu banyak untuk mengurusi rumah, apalagi jika harus bekerja penuh dari pagi hingga sore bahkan malam hari. Bagi beberapa profesi bahkan mengharuskan pergi ke luar kota atau ke luar negeri dalam beberapa hari. Situasi seperti ini mau tidak mau membutuhkan pengertian semua isi keluarga. Kalau antisipasi tidak dilakukan maka keadaan bisa jadi akan lebih buruk dari sekedar tambahan penghasilan. Komunikasi perlahan akan hambar, dan suasana 
rumah menjadi tidak nyaman. pergi. Latihan yang terberat adalah Permaslahan dalam penulisan ini saat melahirkan, ia mempertaruhkan adalah peran ibu rumah tangga dalam antara hidup dan mati. Mati syahid jika perekonomian keluarga, tinjauan sang ibu melahirkan dan harus berakhir hukum Islam terhadap peran istri dalam dengan kematian. Ketika latihan berat mencari nafkah. ini bisa dilalui dengan baik, maka tugas

Peranan wanita dalam aktivitas berat berikutnya juga menanti karena rumah tangga berarti wanita sebagai bersifat fisik dan psikologis.

ibu rumah tangga. Dalam hal ini wanita

Perempuan sebagai istri memiliki $m$ emberikan peran yang sangat peran yang sangat penting. Istri yang penting bagi pembentukan keluarga sejahtera sebagai unit terkecil dalam bijaksana dapat menjadikan rumah kehidupan bermasyarakat, berbangsa, dan bernegara. Kehidupan yang sehat sejahtera harus dapat dimanifestasikan dalam kehidupan sehari-hari.

Di dalam keluarga perempuan dapat berperan sebagai ibu, istri dan anak. Semua peran tersebut menuntut adanya tugas sesuai dengan perannya yang mana peran tersebut juga merupakan keistimewaan mereka.

Peran ibu sangat besar dalam mewujudkan kebahagiaan dan keutuhan keluarga. Sebagai ibu tugas perempuan yang utama ialah mendidik generasi-generasi baru. Mereka memang disiapkan oleh Allah untuk tugas itu, baik secara fisik maupun mental. Allah melatihnya sejak ia mengadung seperti rasa sakit, lemah, mual-mual, pusing atau berbagai keinginan aneh. Kemudian harus membawa janinnya kemana saja ia tangganya sebagai tempat yang paling aman dan menyenangkan bagi suami. Wanita sebagai pendamping suami, secara umum bertugas memenuhi kewajibannya terhadap suami, mendukung/ mendorong semangat untuk keberhasilan suami dalam berbagai hal dan mendoakan suami.

Sabda Nabi Muhammad saw:

"Pengabdianmu kepada suamimu adalah Shodaqoh ( HR. Dailami)."

Dalam ajaran Islam, istri atau ibu tidak diperintahkan atau diwajibkan untuk bekerja. Karena nafkahnya dicukupi suami demikian juga anakanak dan semua kebutuhan rumah tangganya. Kewajiban istri hanya taat dan takut kepada Allah SWT dan suaminya, menjaga diri, keluarga dan harta suaminya ketika ia pergi (ghaib) sesuai dengan Firman Allah dalam AlQur'an Surat An-Nisa': 34 dikatakan: 


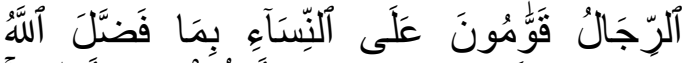

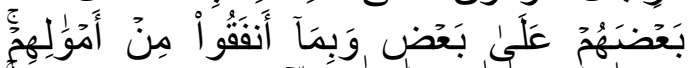

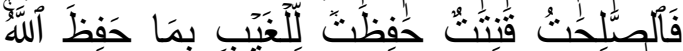

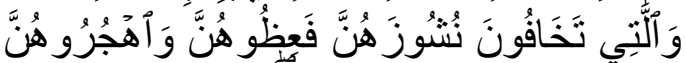

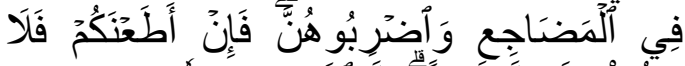

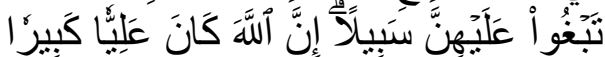

Terjemahannya:

"Kaum laki-laki itu adalah pemimpin bagi kaum wanita, oleh karena Allah telah melebihkan sebahagian mereka (laki-laki) atas sebahagian yang lain (wanita), dan karena mereka (laki-laki) telah menafkahkan sebagian dari harta mereka. Sebab itu maka wanita yang saleh, ialah yang taat kepada Allah lagi memelihara diri ketika suaminya tidak ada, oleh karena Allah telah memelihara (mereka). Wanita-wanita yang kamu khawatirkan nusyuznya, maka nasehatilah mereka dan pisahkanlah mereka di tempat tidur mereka, dan pukullah mereka. Kemudian jika mereka mentaatimu, maka janganlah kamu mencari-cari jalan untuk menyusahkannya. Sesungguhnya Allah Maha Tinggi lagi Maha Besar"

Dengan demikian, maka istri tidak dituntut untuk bekerja mencari nafkah untuk memenuhi kebutuhan hidupnya. Namun dalam kenyataan kita banyak menemui wanita atau istri yang bekerja.

Hukum wanita dalam bekerja telah diatur dalam Islam, hak wanita untuk bekerja telah ditetapkan oleh Islam, wanita yang bekerja harus sesuai dengan tabiatny dan aturanaturan syariat dengan tujuan untuk menjaga kepribadian dan kehormatan wanita.

Islam menjunjung tinggi derajat wanita untuk menjaga kesucian serta ketinggian derajat dan martabat kaum wanita, maka dalam kehidupan seharihari Islam memberikan batasan dan perlindungan bagi kehidupan wanita.

Ajaran Islam menginginkan dan menjamin terwujudnya kemaslahatan dalam kehidupan manusia. Dalam arti bahwa ajaran Islam menghendaki agar menusia menjalani dan menikmati suatu kehidupan yang sejatera dan bahagia terhindar dari derita dan nista baik di dunia maupun di akhirat nanti.

\section{B. METODE PENELITIAN}

Jenis penelitian yang digunakan adalah penelitian kuanlitatif tentang riset yang bersifat deskriptif dan cenderung menggunakan analisis. Proses dan makna (perspektif subjek) lebih ditonjolkan dalam penelitian kualitatif.

Data primer adalah data yang berasal dari sumber asli ataupun pertama. Dalam penelitian ini, menggunakan data primer atau data empiris yang diperoleh dari penyebaran angket. Dalam penelitian ini angket yang tersebar terdiri dari angket tertutup dan angket terbuka. Angket 
tertutup dimana masyarakat telah anggota kelompok tani dan kemudian disediakan pilihan pertanyaan yang akan menjadi objek penelitian.

berkenan dengan pengaruh terapan

peran ibu rumah tangga dalam

menumbuh kembangkan ekonomi keluarga ditinjau dari hukum islam.

Data sekunder merupakan data yang sudah tersedia sehingga kita tinggal mencari dan mengumpulkan. Data sekunder yang diperoleh dari penelitian ini adalah data yang diperoleh peneliti melalui instansi-instansiyang berkaitan dengan penelitian ini. Data sekunder dalam penelitian ini meliputi gambaran umum perusahaan, serta landasan teori yang diperlukan.

Populasi adalah suatu kumpulan menyeluruh dari suatu obyek yang merupakan perhatian peneliti. Populasi pada penelitian ini adalah seluruh masyarkat tani muslim yang tersebar di seluruh wilayah desa buttu batu. Dari jumlah tersebut sebanyak 78 jiwa bekerja sebagai pekerja ibu rumahtangga yang memiliki usaha rumahan yang tergabung dalam
Dalam penelitian ini, teknik pengumpulan data merupakan faktor penting demi keberhasilan penelitian, Metode Pengumpulan Data merupakan teknik atau cara yang dilakukan untuk mengumpulkan data. Adapun tiga teknik pengumpulan data yang biasa digunakan adalah angket, observasi, dan wawancara.

Analisis data dilakukan dengan cara analisis kuantitatif dengan menggunakan metode Partial Least Square (PLS)-PM dan uji hipotesis.

\section{HASIL PENELITIAN DAN PEMBAHASAN}

1. Analisis data

Model analisis yang dipergunakan dalam penelitian ini adalah analisis yang diperoleh dari Pengaruh Peran ibu rumah tangga dalam mndorong kesejahteraan keluarga ditinjau dari hukum islam Partial Least Square Partial Modeling (PLS-PM).

\section{a. Diskripsi Variabel Penelitian}

Tabel C.1 Ekonomi Keluarga

\begin{tabular}{llccccc}
\hline \multirow{2}{*}{ No } & \multirow{2}{*}{ Indikator } & \multicolumn{5}{c}{ Penyataan Responden } \\
\cline { 3 - 7 } & & 5 & 4 & 3 & 2 & 1 \\
\hline 1 & $\mathrm{X}_{1}$ (Al-Qur'an) & 59 & 2 & - & - & - \\
\hline 2 & $\mathrm{X}_{2}$ (As-Sunnah) & 48 & 34 & 2 & - & - \\
\hline 3 & $\mathrm{X}_{3}$ (ljma) & 34 & 26 & 2 & - & - \\
\hline 4 & $\mathrm{X}_{4}$ (Hadits) & 40 & 22 & - & - & - \\
\hline
\end{tabular}


Kesimpulan:

$\mathrm{X}_{1}=$ untuk indikator $\mathrm{X}_{1}$ (AI-Qur'an)yang

memilih kategori sangat setujuh

:59. Indikator ini mampu memengaruhi variabel hukum islam.

$\mathrm{X}_{2}=$ untuk indikator $\mathrm{X}_{2}$ (As-Sunnah) yang memiliki kategori sangat setujuh : 48. Indikator ini mampu memengaruhi variabel hukum islam
$X_{3}=$ untuk indikator $X_{3}$ (ljma) yang memiliki kategori sangat setuju setujuh : 47.Indikator ini mampu memengaruhi variabel hukum islam.

$\mathrm{X}_{4}=$ untuk indikator $\mathrm{X}_{4}$ (Hadits) yang memiliki kategori sangat setujuh : 40. Indikator ini mampu memengaruhi variabel hukum islam.

Tabel C. 2 Peran Ibu

\begin{tabular}{clccccc}
\hline \multirow{2}{*}{ No } & \multirow{2}{*}{ Indikator } & \multicolumn{5}{c}{ Pernyataan Responden } \\
\cline { 3 - 7 } & & 5 & 4 & 3 & 2 & 1 \\
\hline 1 & $\mathrm{X}_{5}$ (Perempuan sebagai ibu) & 51 & 22 & - & - & - \\
\hline 2 & $\mathrm{X}_{6}$ (perempuan sebagai istri) & 29 & 33 & - & - & - \\
\hline 3 & $\mathrm{X}_{7}$ (perempuan pendidik anak) & 25 & 37 & - & - & - \\
\hline 4 & $\mathrm{X}_{8}$ (wanita karir) & 27 & 35 & - & - & - \\
\hline
\end{tabular}

Kesimpulan:

$\mathrm{X}_{5}=$ untuk Indikator (Perempuan sebai ibu) yang memiliki kategori sangat setujuh sebanyak : 51 . Indikator ini mampu memengaruhi variabel peran ibu.

$\mathrm{X}_{6}=$ untuk Indikator (Pperempuan sebagi istri) yang memiliki kategori setujuh sebanyak : 33. Indikator ini mampu memengaruhi Variabel peran ibu.
$\mathrm{X}_{7}=$ untuk Indikator (Perempuan pendidik anak) yang memiliki kategori setujuh sebanyak : 37 . Indikator ini mampu memengaruhi variabel peran ibu.

$\mathrm{X}_{8}=$ untuk Indikator (wanita karir) yang memiliki kategori setujuh sebanyak : 37. Indikator ini mampu memengaruhi variabel penjualan peran ibu. 
Tabel C.3 Hukum Islam

\begin{tabular}{ccccccc}
\hline \multirow{2}{*}{ No } & Indikator & \multicolumn{5}{c}{ Pernyataan Responden } \\
\cline { 3 - 7 } & & 5 & 4 & 3 & 2 & 1 \\
\hline 1 & $\mathrm{Y}_{1}$ (lbadah teratur) & 58 & 4 & - & - & - \\
\hline 2 & $\mathrm{Y}_{2}$ (Bermasyarakat) & 50 & 11 & 1 & - & - \\
\hline 3 & $\mathrm{Y}_{3}$ (Ada tabungan) & 35 & 26 & 1 & - & - \\
\hline 4 & $\mathrm{Y}_{4}$ (Tidak ada tabungan) & 25 & 37 & - & - & - \\
\hline
\end{tabular}

Kesimpulan :

Y1 = untuk Indikator (ibadah) yang memiliki kategori sangat setujuh : $\mathrm{Y} 4=$ sebanyak 58. Indikator ini mampu memengaruhi variabel ekonomi keluarga.

$\mathrm{Y} 2=$ untuk Indikator (bermasyarakat) yang memiliki kategori setujuh sangat sebanyak 50 . Indikator ini mampu memengaruhi variabel ekonomi keluarga.

Y3 = untuk Indikator (ada tabungan) yang memiliki kategori sangat dibawah ini menunjukkan indikator setujuh sebanyak 35 . Indikator ini reflektif

\section{Gambar C.1 Indicator Reflektif}

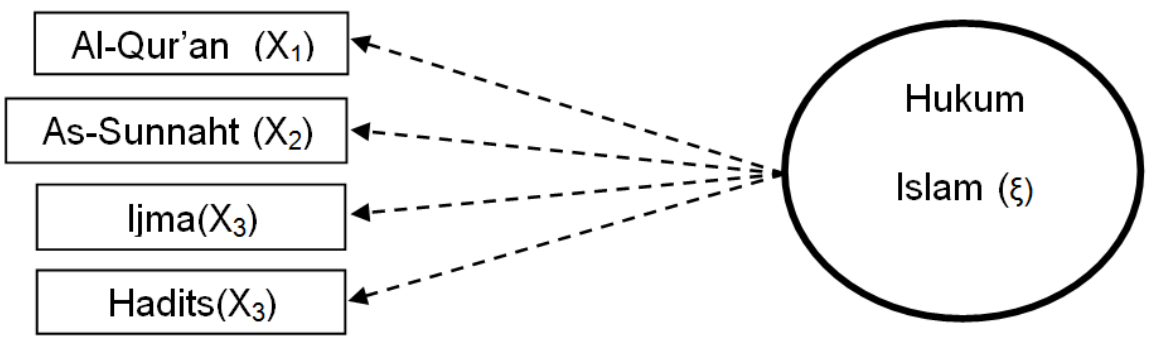

Model pengukuran atau outer indikator dapat dilihat dari nilai loading model dengan indikator reflektif di faktor (standardized loading) nilai ini evaluasi dengan Convergent dan mengambarkan besarnya korelasi decriment validity. Untuk validitasi antara tiap indikator akan valid bila 
memiliki nilai standardized loading lebih reliability (validitasi indicator) reliability dari 0,5. Berdasarkan loading factor variable dimulai Average Varibel correlation (dimension). Dan untuk Extrated (AVE).

Evaluasiconfergent validity meliputi

Tabel C.4 Correlations (Dimension)

\begin{tabular}{lccccc}
\hline \multicolumn{1}{c}{$\begin{array}{c}\text { Laten } \\
\text { Variable }\end{array}$} & $\begin{array}{c}\text { Manifest } \\
\text { variable }\end{array}$ & $\begin{array}{c}\text { Standardiz } \\
\text { ed }\end{array}$ & Loadings & Location & Communalities \\
& $s$ & loadings & & & \\
\hline Hukum & $\mathrm{X}_{1}$ & 0,467 & 0,467 & 0,000 & 0,218 \\
Islam & $\mathrm{X}_{2}$ & 0,658 & 0,658 & 0,000 & 0,433 \\
& $\mathrm{X}_{3}$ & 0,812 & 0,812 & 0,000 & 0,659 \\
& $\mathrm{X}_{4}$ & 0,744 & 0,744 & 0,000 & 0,554 \\
\hline Peran ibu & $\mathrm{X}_{5}$ & 0,407 & 0,407 & 0,000 & 0,166 \\
& $\mathrm{X}_{6}$ & 0,734 & 0,734 & 0,000 & 0,538 \\
& $\mathrm{X}_{7}$ & 0,847 & 0,847 & 0,000 & 0,718 \\
& $\mathrm{X}_{8}$ & 0,172 & 0,172 & 0,000 & 0,030 \\
& & & & & \\
\hline Ekonomi & $\mathrm{Y}_{1}$ & 0,373 & 0,373 & 0,000 & 0,129 \\
Keluarga & $\mathrm{Y}_{2}$ & 0,704 & 0,704 & 0,000 & 0,459 \\
& $\mathrm{Y}_{3}$ & 0,884 & 0,884 & 0,000 & 0,724 \\
& $\mathrm{Y}_{4}$ & 0,317 & 0,317 & 0,000 & 0,093
\end{tabular}

Sumber : hasil olahan data menggunakan PLS-PM

Berdasarkan tabel C.4 di atas $X_{1}$ (Al-quran) nilai loading $=467>0,05$ dapat dilihat bahwa nilai indikator yang memiliki korelasi dengan variabel sangat valid terhadap variabel Hukum Islam adalah dimana nilai $X_{2}$ (Hadis) nilai loading $=0,658>0,05$ standardized loading untuk indikator

$$
\begin{aligned}
& X_{1}=0,467>0,5 \\
& X_{2}=0,658>0,5 \\
& X_{3}=0,812>0,5 \\
& X_{4}=0,744>0,5
\end{aligned}
$$
hukum islam $=0,516$ sangat valid terhadap variabel hukum islam $=0,501$

$\mathrm{X}_{3}$ (ljma') nilai loading $=0,812>0,05$ sangat valid terhadap variabel hukum islam $=0,554$

Untuk: 
$\mathrm{X}_{4}$ (As-Sunnah) nilai $=0,744>0,05$ peran ibu adalah Berdasarkan loading sangat valid terhadap variabel factor correlation (dimension) dimana hukum islam nilai standardized loading adalah:

Kemudian untuk melihat nilai

indikator yang memiliki korelasi dengan

\section{Gambar C.2 Loading Factor Correlation (Dimension)}

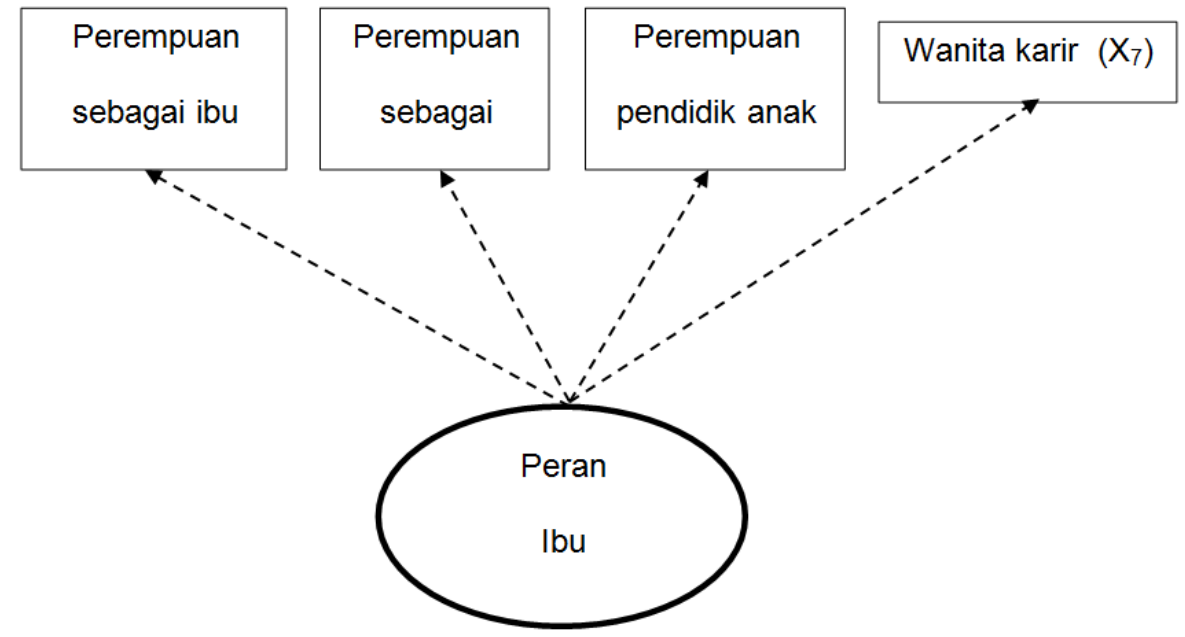

$$
\begin{aligned}
& X_{5}=0,407>0,5 \\
& X_{6}=0,734>0,5 \\
& X_{7}=0,847>0,5 \\
& X_{8}=0,172>0,5
\end{aligned}
$$

Untuk

$\mathrm{X}_{5}$ (Perempuan sebagai ibu) nilai loading $=0,407>0,5$ sangat valid terhadap variabel peran ibu $=0,423$.

$\mathrm{X}_{6}$ (Perempuan sebagai istri) nilai loading $=0,686>0,5$ valid terhadap variabel peran ibu $=0,751$.
$\mathrm{X}_{7}$ (Perempuan pendidik anak) nilai loading $=0,691>0,5$ valid terhadap variabel peran ibu $=0,843$.

$\mathrm{X}_{8}$ (wanita karir) nilai loading $=0,172>$ 0,5 sangat valid terhadap variabel peran ibu $=0,361$.

Kemudian untuk melihat nilai indikator yang memiliki korelasi dengan variabel ekonomi keluarga adalah Berdasarkan loading factor correlation (dimension) dimana nilai standardized loading diatas adalah 
Gambar 4.5 Loading Factor Correlation (Dimension)

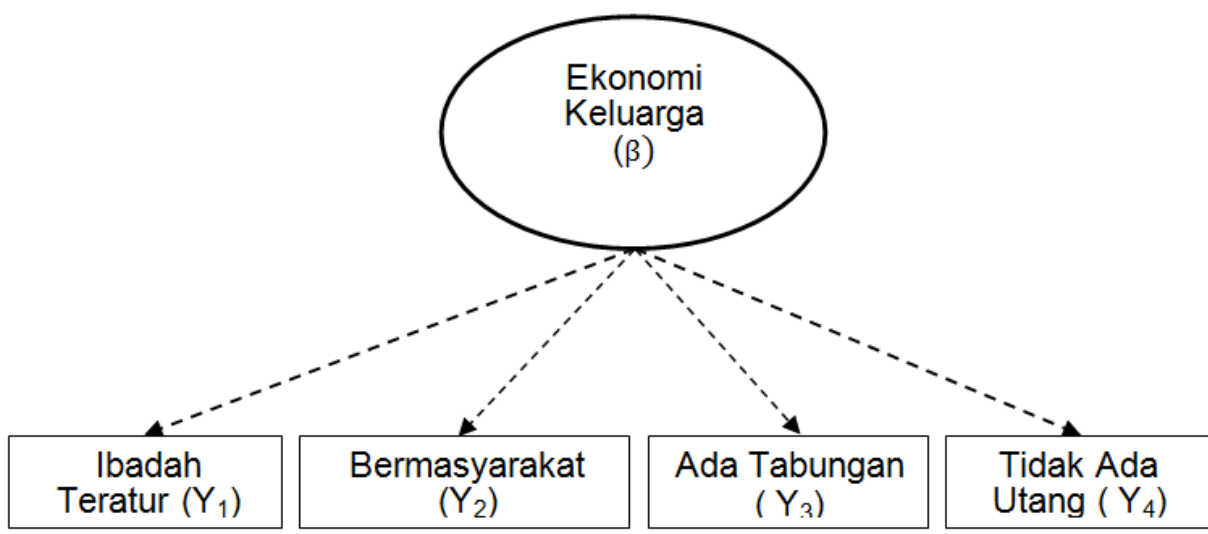

$Y_{1}=0,373>0,5$

$\mathrm{Y}_{2}=0,704>0,5$

$\mathrm{Y}_{3}=0,884>0,5$

$Y_{4}=0,317>0,5$

Untuk

$\mathrm{Y}_{1}$ (Ibadah teratur) nilai loading $=$ $373>0,5$ sangat valid terhadap variabel ekonomi keluarga $(\beta)=$ 0,430

Y2 (Bermasyarakat) nilai loading = $0,704>0,5$ sangat valid terhadap variabel ekonomi keluarga $(\beta)=$ 0,721 .

Y3 (Ada tabungan) nilai loading = $0,884>0,5$ valid terhadap variabel ekonomi keluarga $(\beta)=0,649$

Y4 (Tidak ada utang) nilai loding = $0,317>0,5$ sangat valit terhadap variabel ekonomi keluarga $(\beta)=$ 0,339

Untuk mengukur atau menguji nilai loading faktor di indikator dilihat pengukuran dari hasil Critical Ratio $(C R)$ pengukuran ini dari hasil nilai standardized loading yang diperoleh dari bostrapping dengan standar caranya. $\mathrm{CR}=$ nilai statistik maka dapat dilihat dari loading factor Composit Reliability.

Hipotesis 1: Diduga Variabel peran ibu berpengaruh Terhadap Variabel ekonomi keluarga

Hasil pengujian outer model yang telah dilakukan menunjukkan bahwa hubungan antara variabel peran ibu memiliki pengaruh antara variabel ekonomi keluarga sebesar 0,805. Sedangkan berdasarkan tabel distribusi $\mathrm{t}$ menunjukkan bahwa $\mathrm{t}$ hitung $=0,805$ lebih kecil dari $t$ tabel $=1,644$ dengan taraf signifikan 0,05 yang menunjukkan bahwa pada hipotesis 1 tidak diterima karena berpengaruh yang signifikan antara variabel peran ibu dengan variabel ekonomi keluarga. 
Hipotesis 2: Diduga Variabel hukum signifikan antara variabel hukum islam islam mempengaruhi Variabel peran dengan variabel peran ibu.

\section{ibu}

Hasil pengujian outer model

yang telah dilakukan menunjukkan

bahwa hubungan antara variabel

hukum islam memengaruhi variabel

peran ibu sebesar 0,923. Sedangkan

berdasarkan tabel distribusi $t$

menunjukkan bahwa $\mathrm{t}$ hitung $=0,923$

lebih kecil dari $t$ tabel $=1,644$ dengan

taraf signifikan 0,05 yang menunjukkan

bahwa pada hipotesis 2 tidak diterima

karena ida terdapat pengaruh yang

\section{KESIMPULAN}

Variabel peran ibu tidak berpengaruh terhadap variabel ekonomi keluarga. Hal ini menunjukkan bahwa hubungan antara variabelperan ibukurang memengaruhi variabel ekonomi keluarga yang signifikan.

Variabel hukum Islam berpengaruh terhadap variabel. Hal ini peran menunjukkan bahwa hubungan antara variabel hukum islam kurang memengaruhi variabel peran ibu.

\section{DAFTAR PUSTAKA}

Abdullah, Irwan. "Reproduksi Ketimpangan Gender Partisipasi Wanita Dalam Kegiatan Ekonomi” Prisma Majalah Ekonomi dan Soaial. No. 6 Tahun 1995. LP3ES.

Arief, Nurhaeni. 2008. Engkau Bidadari Para Penghuni Surga, Kisah Teladan Wanita Saleha.Yogyakarta: Kafila.

Azis, Asamaeny. 2016. Kesetaraan Gender dalam Perspektif Sosial Budaya. Makassar:Yapma.

Bafaqih. 2003. Single Parent; Peran Ganda Ibu dalam Mendidik Anak. Bogor: Cahaya.

Cholid, Narbuko dan Achmadi Abu. 2008. Metodologi Penelitian. Jakarta: Bumi Aksara.

Dahlan, Juariyah. 1994. "Wanita Karir". Jurnal IAIN Sunan Ampel Edisi XII. Surabaya,

Engineer, Asghar Ali, Penerj. Agus Nuryanto. 2003. Pembebasan Perempuan. Cet. I; Yogyakarta: LkiS.

Al-Ghaffar, Abdur Rasul Abdul Hasan. 1993. Wanita Islam dan Gaya Hidup Modern. Jakarta: Pustaka Hidayah. 
Moleong, Lexy J. 2010. Metode Penelitian Kualitatif. Bandung: Remaja Rosda Karya. 2005. Metode Penelitian Kualitatif Edisi Revisi. Bandung: PT Remaja Rosdakarya.

Ridjal, Fauzie dkk. 1993. Eds. Dinamika Gerakan Perempuan di Indonesia. Yogyakarta: TiaraWacana.

Sajogyo, Pudjiwati. 1985. Peranan Perempuan dalam Perkembangan Masyarakat Desa. Jakarta: Rajawali.

Sugiono. 2005. Memahami Penelitian Kualitatif. Bandung: Alfabeta.

Suliem, Handewi P. "Potensi dan Partisipasi Wanita Dalam kegiatan Ekonomi Pedesaan". Prisma Majalah Kajian Ekonomi dan Sosial No. 6 tahun 1992, LP3ES

Taman, Muslich. 2008. Pesona Dua Ummul Mukminin, Teladan Terbaik Menjadi Wanita Sukses dan Mulia. Jakarta: Pustaka Al-Kautsar

Willis, Sofyan. 2012. Sosiologi Keluarga. Bandung: Alfabeta. 